\title{
Direction and Construction in landscape regions with mountains and waters
}

\author{
Lina Zhang ${ }^{1, \text { a }}$, Hong Wang ${ }^{1, \mathrm{~b}}$ Jing $\mathrm{Yu}^{2, \mathrm{c}}$ Jing Zhang ${ }^{2, \mathrm{~d}}$ and Yong Zhang ${ }^{2, \mathrm{e}}$ \\ ${ }_{1}^{1} 18$ Chaowang Road, Hangzhou, China \\ ${ }^{2}$ 828Yuhangtang Road, Hangzhou, China

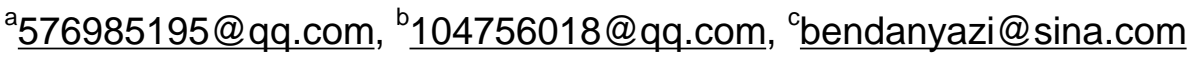

Keywords: Landscape region. Direction. Control.

Abstract. Recently, rapid construction development in landscape regions with mountains and waters has greatly affected natural landscape characteristics in the regions. This article aims to provide targeted planning control and guidance for regional development using design concept of zoning and classification with consideration of site features, and introducing control index according to the scale of the targeted region. Using the project in Qiandao Lake as an example, the article offers zoning of space control, building capacity and volume control, setback of buildings, spatial relationships, color, material and style, and analyzes how to manage coastal lines, utilize sites, build road along the landscape and other design elements.

\section{Introduction}

The landscape regions with picturesque scenery, superior locations and its associated infrastructure conditions have been becoming hot spots for land development. However, due to the lack of specific planning control and guidance, past and current construction activities often lead to destructive results and have seriously affected the style and features of mountains and waters. The current urban planning regulations and guidance are not fully applicable for land development in this type of regions which have higher ecological sensitivity, require better landscape, and are more complicated in land use. Therefore it is necessary to undertake planning analysis and develop control methods for effectively controlling the development behavior as well as maintaining nature scenery in landscape regions. The article further introduces the organized and healthy land development and conservation in this type of regions through specifically designed control measures.

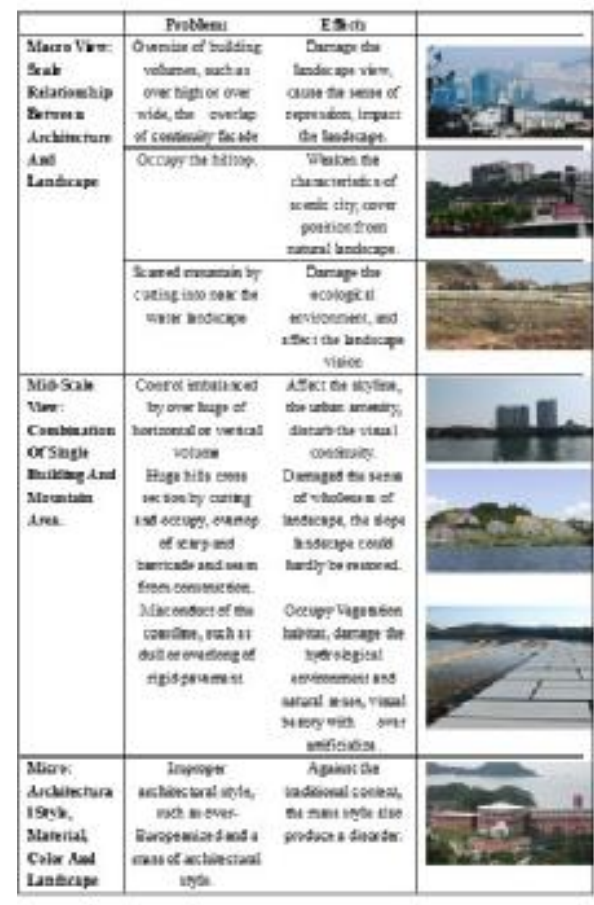

Fig. 1, Problems Classify

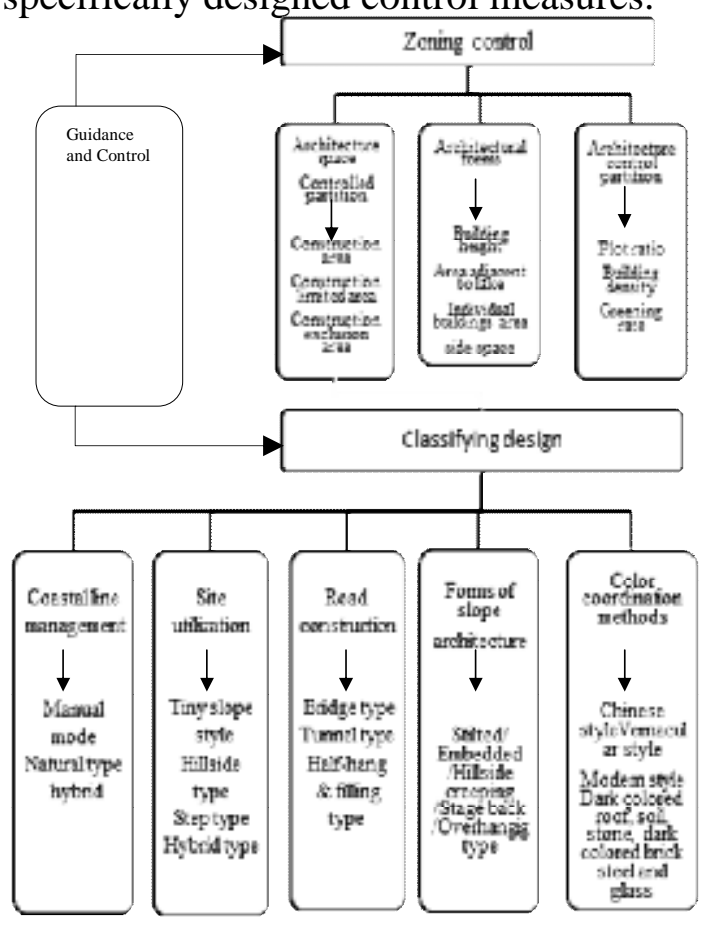

Fig. 2, Direction for Urban Construction. 


\section{Construction Problem Exists In Landscape Regions with Mountains and Waters}

With the accelerating pace of urbanization and increasing accessibility between cities and suburbs, people living in an increasingly stress and fast-paced life style begin to choose scenic area along the outer edge of the city for leisure activities. While the current control regulations focus on methods of controlling land usage and block land construction index, due to the lack of planning control and guidance for the development of landscape regions, the regions are facing serious environmental problems as a result of increasingly unplanned development.

Taking Hangzhou Qiandao Lake as an example, we list the major problems existed in the current development and construction in the landscape regions from the different prospective, in Fig. 1.

\section{Research on the Direct Construction of Landscape Area}

The core concept of urban planning aims to control the land usage purpose and intensity, and to form an indicator system to control "purpose, quantity, position and boundary". The system is divided into two parts: mandatory content and guidance content. The mandatory content includes land usage, plot ratio, building density, green space ratio, building height limit, building setback line, the entrance location and direction and the number of parking spaces etc. The guidance content includes the color and style of buildings, density of registered occupants, supporting facilities etc. Currently, the control system of the urban regulatory plan emphasizes on the development of the quantity control not the specific image and landscape control.

Given the unique features, high sensitivity and vulnerability of the landscape regions, the control regulations should consider protecting the environment and the public interest as primary purpose, and then identify development control requirements to coordinate the relationships between landscape protection and resource utilization. Based on this principle, we propose the control methods for zoning control and classification design guidance to improve the control measures for the scenic environment, identify the appropriate scopes for zoning, index requirements and control measures, and provide clear direction for urban construction of landscape regions by setting indexes and regulations as in Fig. 2.

\section{Zoning Control}

\section{Building Space Zoning Control}

Development Feasibility Analysis: The three-dimensional GIS spatial simulation and terrain analysis techniques are used to analyze the elevation, aspect and slope of the site. The collective information is then compiled and used to classify the region as suitable, restricted or unsuitable.

Ecologic Landscape Sensitivity Analysis: By analyzing the relationships between the main viewing areas, the position of the mountain and native vegetation, ecologic sensitivity can be classified as high, medium and low.

Combining two aspects of analysis above, the block of the land is then classified as construction area, construction limited area or/and construction exclusive area as detailed in Fig. 3 and Fig.1.

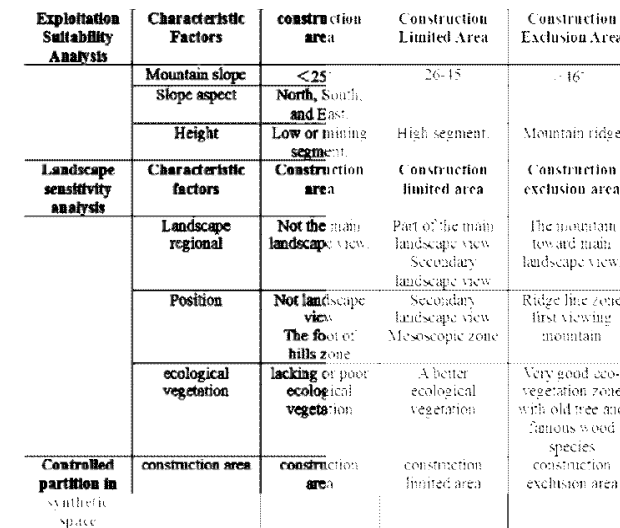

Fig. 3. Land Classify.

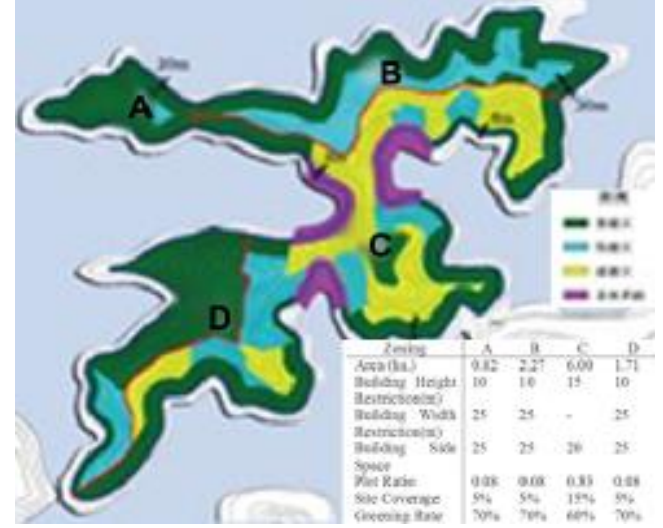

Fig.1. Control Zoning

\section{Architectural Form Control Zoning}


The traditional regulatory plan controls building height in construction development within a block of land. However in landscape regions, apart from controlling dimension (including height, length and width) of a single building to appropriate form. To allow the beautiful landscape to show it is necessary to have voids between the buildings, meaning the overlapped facade of a group of buildings should not be too large, regardless of the volume of an individual building. The scale of the overlapped buildings is directly affected by the dimension of the mountain. Therefore the architectural form control needs to consider building height and frontage, facade area of individual building and facade area of the whole building group with water-view, as well as distance between the buildings, the ratio control over the premier viewing front of the mountain and the overall building façade area, as described in Fig. 4.

\begin{tabular}{|c|c|}
\hline $\begin{array}{c}\text { Comitrul } \\
\text { Comlemis }\end{array}$ & Гasis ol' Cum trol \\
\hline Plot ratio & 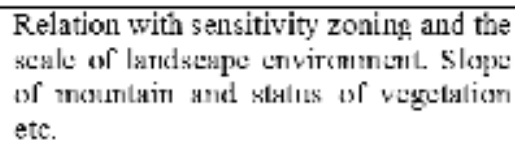 \\
\hline $\begin{array}{l}\text { Buildine } \\
\text { height- } \\
\text { limilds } \\
\text { width- } \\
\text { limit }\end{array}$ & 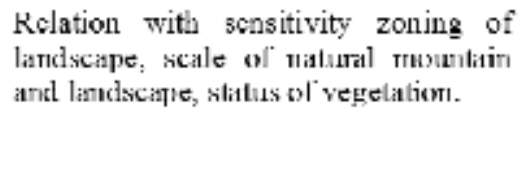 \\
\hline $\begin{array}{l}\text { Surliace } \\
\text { towards } \\
\text { lake }\end{array}$ & 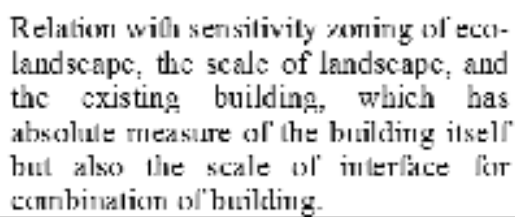 \\
\hline $\begin{array}{l}\text { Irulividus } \\
\text { buildirig } \\
\text { area }\end{array}$ & $\begin{array}{l}\text { Relation with the scale of ervirominent, } \\
\text { the scale of existimg buildting and } \\
\text { vegetation, also the construction } \\
\text { requirements of concentrating. }\end{array}$ \\
\hline $\begin{array}{l}\text { T.aleral } \\
\text { spacing of } \\
\text { buildings }\end{array}$ & $\begin{array}{l}\text { Relation with sensilivily aming of } \\
\text { landscape, constmuction face width and } \\
\text { depth, the species of vegetation status } \\
\text { and also the cover degrec etc... }\end{array}$ \\
\hline
\end{tabular}

Fig. 4, Control Contents.

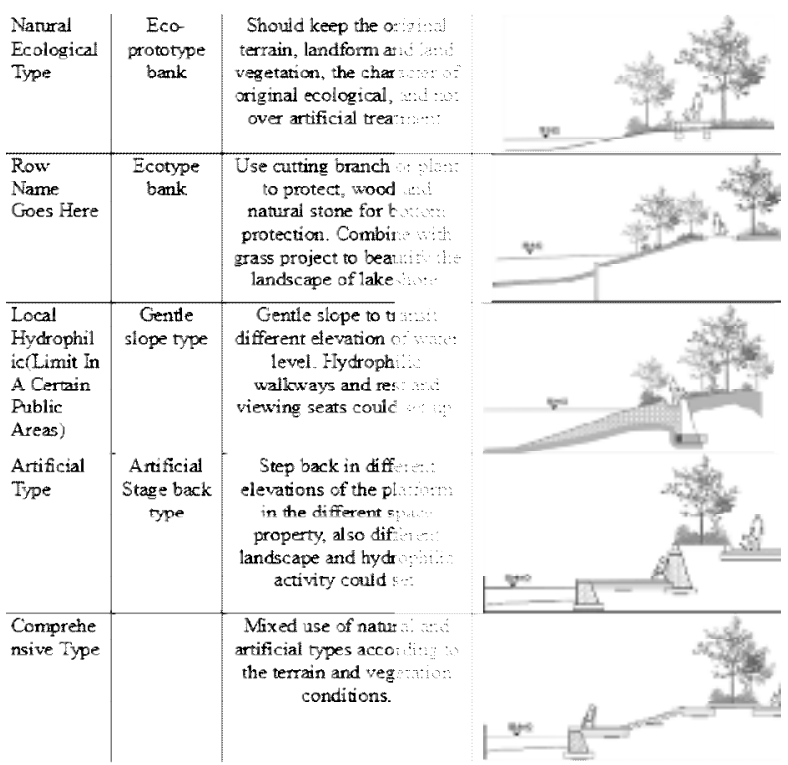

Fig. 5, Coastal Line Management.

\section{Classifying Design}

Protecting ecological environment and maintaining the original landscape feature are essential requirement for the commercial construction development within landscape regions. Our classification design guidance includes coastal line management, site utilization methods, 
construction of road along the scenic side, building types along hillside, construction style and color coordination methods etc.

\section{Coastal Line Management}

Coastline management emphasize on maintaining landscape ecology. In principle, an appropriate distance need to be setback from coastline to form an eco-green belt. No waterfront construction is allowed within the belt to protect scenic landscape. The construction of public leisure facilities can be partially built close to water. However, the length of the artificial coastline should be under controlled. Based on characteristics of terrains and slope, the treatments outlined in Fig. 5 can be adopted to manage nature coastline.

\section{Control of the Relationship between the Buildings or Structures with Mountain}

The height of buildings along hillside should meet the requirement that the upper one third of the mountain should be fully visible from the view point. The continuous surface of landscape orientation for the buildings facing lake should no longer than one half of the width for the first viewing mountain. The space between buildings should be wider than 6 meters and also should be wider then 1/5 length of continuous building at the same time. Otherwise the height of the scarp should not be greater than $3 \mathrm{~m}$, the height of the overhanging should not be greater than $5 \mathrm{~m}$, in order to shelter the retaining wall for the trees Fig. 7.

\section{Site Utilization Methods}

The principle of site utilization is to integrate buildings into terrain of local landscape and to limit earthwork. The particular methods include overhead, flat slope, stage back, hillside and hybrid etc., Different treatment methods are adopted according to the different slope of the mountain as listed in Fig. 6.
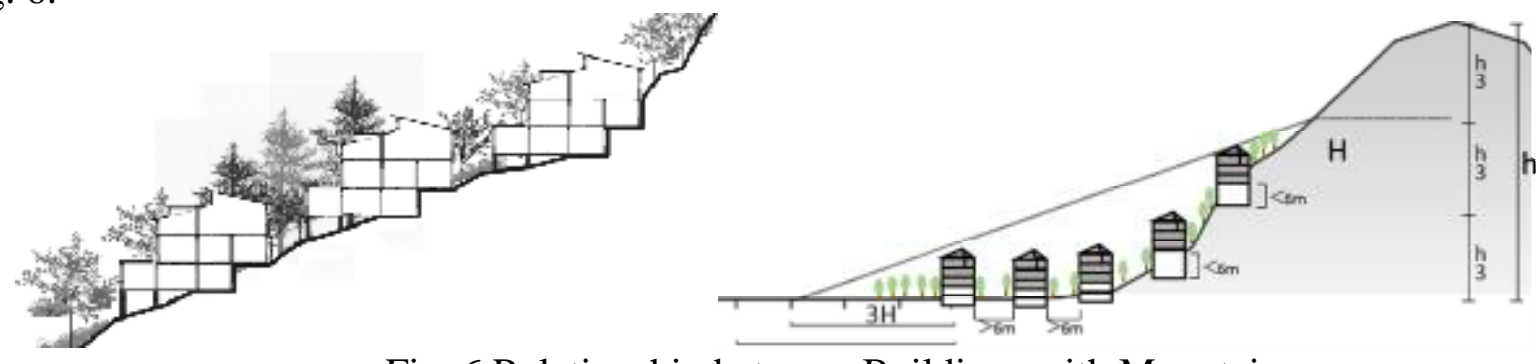

Fig. 6 Relationship between Buildings with Mountain.

\section{Road Construction along Hillside}

Since the construction of roadway can cause destructive effect to abrupt slope hills, it is necessary, when planning the development and construction of the landscape regions with mountains and waters, to first limit number of vehicle lanes and to control the width of the roadway, and also appropriately minimize the earthwork required by constructing the roadway. Fig. 8 details specific methods dealing with roadway construction in landscape region, as overhead type, overhanging type, half-hang \& filling type, embedded type and tunnel type etc.

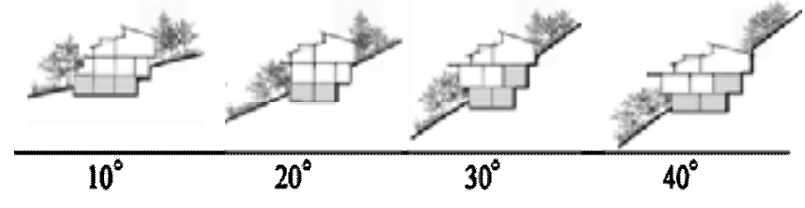

Fig. 7 Treatment Methods of Different Slope.
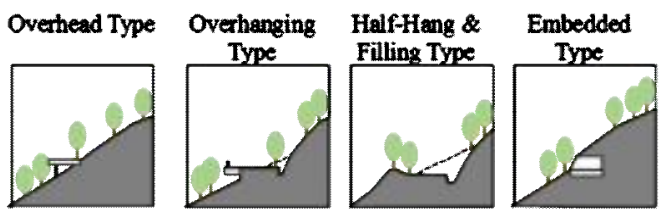

Fig. 8 Forms of Road Construction.

\section{Architecture Forms along Slope Sites}

As for individual building control, the regulatory control requirements for urban planning can be referenced and selectively adopted in construction of a large scale of buildings in flat terrain sites. The primary aim of this paper is to study control measures for the development and construction of mountain area in the landscape regions with mountains and waters. The scales of terrain of landscape and its natural environment, controlling the dimension of buildings are things to be considered first in planning stage. It is also required for buildings to be integrated with the slope of the mountain. 
Architecture styles suitable for buildings along slope sites are stilted type, embedded type, hillside creeping type, stage back type and overhanging type etc., detailed in Fig. 9

\section{Construction Style and Color Coordination Methods.}

Chinese style is more appropriate for construction than European style, traditional style than western-style, transparent than bright. Dark color would be preferable over light color for buildings. New building derived from nature are becoming part of nature. The building style could adopt from traditional Chinese to modern Chinese style, classic to modern local style, modern style, underground or semi-underground style and overhead style etc. Exterior wall can make use of nature texture of stone, bamboo, wood, soil, darker metallic and glass etc. In addition, the green building covered with plants and ensconced building is also suitable for the construction in landscape regions with mountains and waters, detailed in Fig. 10.

\section{Research Outcomes}

Based on the proposed control index systems above, we arrange the regulation control into two parts: the first is the traditional plan, which is the legal documentation to define the scopes of land usage, development intensity and public basic infrastructure. The control elements must generally be general and simple so that the research outcomes can be formed as a simple and clear interface, as shown in the figure below. The process of regulatory plan shall initiate with positioning the major roads for urban development, then outline the alignment of bypass without changing road grade. Under the condition of maintaining the surface area and not affecting the main landscape surface, site boundary can be adjusted locally according to terrain, vegetation and landscape etc.

The second part is the management documentation corresponding to the control of zoning and classification design. For some control elements which are difficult to formulate in a simple text and data based expression, the method based on pattern induction would be found more intuitive. That is to deliver more pertinent modes to different elements, and then to outline scope for a certain pattern in different blocks. Regardless recommendation being selected or not, these modes offer land users a choice, and also provide basis for planning administrative department to assess and approve the proposal, such as approaches used in shore water waterfront
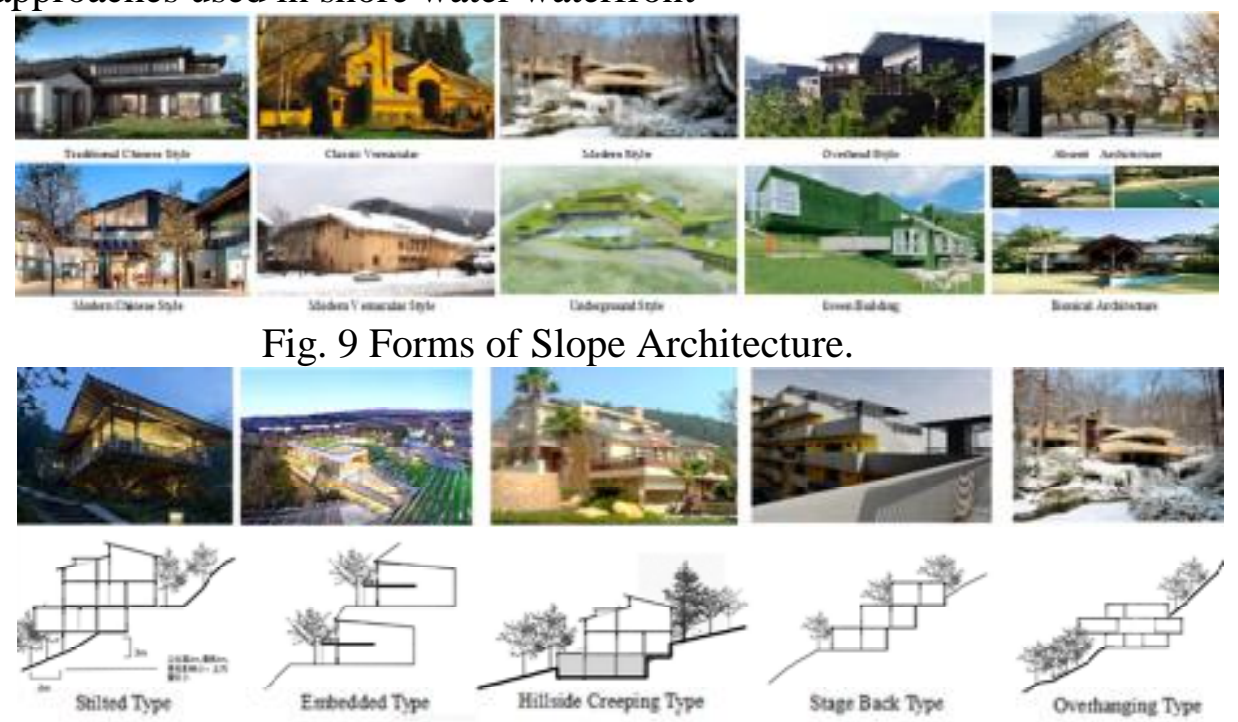

Fig. 9 Forms of Slope Architecture.
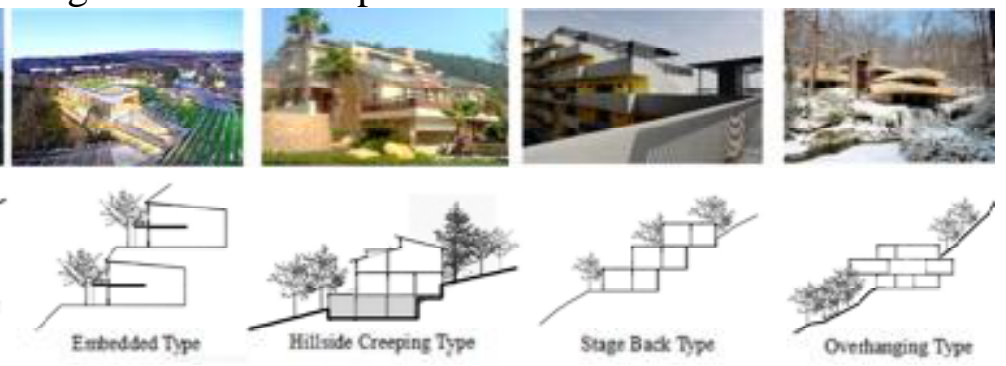

Fig. 10 Construction Style.

\section{Conclusions}

Research on the control and construction based on zoning and classification design of landscape regions with mountains and waters has been undertaken for many years. After practice test and implementation of the proposed method in the planning and construction of the QianDao lake National Scenic Area, the method has been demonstrated to result in an excellent control over 
protecting character of the main scenic landscape and formulating the well-organized development of commercial properties.

\section{References}

[1] Yu Jing: Regulatory detailed planning of tourist resort featured by lake and mountain. Zhejiang Fifth urban\& rural planning design institute (2010), p. 32

[2] Wang Yingying: Research of shoreline construction problem in urban waterfront green space countermeasure. Anhui Agricultural University (2012), p. 16.

[3] Jia Manli: Research of landscape character planning in scenic area tourism town. Hebei Agricultural University (2009), p. 36

[4] Chen Xutong: Discussion of researching and designing the friendly embankment in urban waterfront space. Northwest A\&F University (2011), p. 26

[5] Zhang Jing and Zhang Yong: Discussion of the system of control system on classification and guide in scenic area with lake and mountain. Zhejiang Urban \& Rural Planning and Designing Institute (2009), p. 3 